\title{
CONSCIOUS THOUGHT AND THE LIMITS OF RESTRICTIVISM
}

\author{
MARTA JORBA \\ Department of Philosophy \\ University of Girona \\ jorba.marta@gmail.com
}

SUMMARY: How should we characterize the nature of conscious occurrent thought? In the last few years, a rather unexplored topic has appeared in philosophy of mind: cognitive phenomenology or the phenomenal character of cognitive mental episodes. In this paper I firstly present the motivation for cognitive phenomenology views through phenomenal contrast cases, taken as a challenge for their opponents. Secondly, I explore the stance against cognitive phenomenology views proposed by Restrictivism, classifying it in two strategies, sensory restrictivism and accompanying states. On the one hand, I problematize the role of attention adopted by sensory restrictivism and I present and discuss in detail an argument that defends the limitation of sensory phenomenology so as to explain the distinction between visual and cognitive mental episodes on the basis of immediate experience. On the other hand, I address accompanying states views by discussing the empirical studies of Hurlburt et al. $(2006,2008)$ that defend the existence of "unsymbolized thinking". I present how they can be construed as evidence for cognitive phenomenology views and I dispel some problems that have been raised against its acceptance. I thus conclude that cognitive phenomenology views hold up well against the restrictivist positions considered.

KEY WORDS: cognitive phenomenology, sensory phenomenology, phenomenal consciousness, experience, unsymbolized thinking

RESUMEN: ¿Cómo debemos caracterizar la naturaleza del pensamiento consciente ocurrente? Recientemente en filosofía de la mente ha surgido un tema muy poco explorado: la fenomenología cognitiva o el carácter fenoménico de los episodios mentales cognitivos. En este artículo presento en primer lugar la motivación de los defensores de la fenomenología cognitiva a través de casos de contraste fenoménico que se pueden considerar un reto para sus oponentes. En segundo lugar exploro la posición en contra de la fenomenología cognitiva que el restrictivismo defiende clasificándolo en dos estrategias: restrictivismo sensorial y estados acompañantes. Por un lado problematizo el papel de la atención que adopta el restrictivismo sensorial y presento y discuto en detalle un argumento que defiende los límites de la fenomenología sensorial para explicar la distinción entre los episodios visuales y cognitivos sobre la base de la experiencia inmediata. Por otro, discuto la estrategia de estados acompañantes a través de los estudios empíricos de Hurlburt et al. (2006, 2008) que defienden la existencia del "pensamiento no simbólico". Muestro cómo estos estudios pueden ser evidencia para la fenomenología cognitiva y disipo algunos problemas que se han planteado contra su aceptación. Concluyo finalmente que los 
defensores de la fenomenología cognitiva se encuentran en una buena posición frente a las visiones restrictivistas consideradas.

PALABRAS CLAVE: fenomenología cognitiva, fenomenología sensorial, conciencia fenoménica, experiencia, pensamiento no simbólico

\section{Introduction}

The nature of occurrent conscious thought is an issue that has occupied philosophers since ancient times. In the past recent years and in the context of a growing interest in consciousness studies, a rather unexplored topic has appeared in philosophy of mind: cognitive phenomenology or the phenomenal character of cognitive mental episodes ${ }^{1}$ (Bayne and Montague 2011b). This question focuses on whether thought is or can be phenomenally conscious, that is, whether there is something it is like to think, drawing on Nagel's (1974) characterization of what-it-is-likeness or phenomenal character. We can adopt different positions towards this question. On the one hand, there is a family of views that defend the idea that conscious thought has a specific phenomenal character, namely, something that we can call the cognitive phenomenology (Strawson 1994/2010; Siewert 1998; Horgan and Tienson 2002; Pitt 2004, 2009; Chudnoff 2011; Smith 2011; Kriegel 2015; Jorba forthcoming, Jorba and Vicente 2014, among others). I will refer to such views as cognitive phenomenology views. On the other hand, we find cognitive phenomenology eliminativists, which deny the existence of cognitive phenomenology and therefore give a negative answer to our question. The general claim behind views within the latter option is that noncognitive kinds of phenomenal character, like sensory or emotional phenomenology, are sufficient to explain the nature of the phenomenal character of thought, so we do not need to posit a cognitive kind of phenomenology (Carruthers and Veillet 2011; Jackendoff 1987; Lormand 1996; Prinz 2011; Robinson 2005; Tye and Wright 2011, among others).

This question is closely related to that of the reach of phenomenal consciousness (Bayne 2009), which can be cashed out in terms of which kinds of mental episodes possess specific phenomenal character and which do not. As general views regarding the reach question, we can distinguish between expansionist and restrictivist views (Prinz 2011). These labels normally include different views and characteri-

\footnotetext{
${ }^{1}$ I use "episode" as an ontologically neutral term that can include states, processes, events, etc. For a discussion on the temporality and ontological character of thought, see Jorba 2015.
} 
zations, ${ }^{2}$ but in a broad way, restrictivists limit the extension of phenomenally conscious states to sensory and perceptual experiences, or even the emotional domain, while expansionists tend to include other kinds of mental states (such as high level perceptual states, emotions and affects, etc.) as phenomenally conscious by themselves, and thus they normally also include thought. The two views presented above are thus related to the question of the reach of phenomenal consciousness in the following way: cognitive phenomenology views are instances of expansionism, whereas phenomenal eliminativist views are instances of restrictivist views. From now on I will adopt the "restrictivist" label as covering positions against cognitive phenomenology views. The result of the debate around cognitive phenomenology, thus, has bearings on the issue of the extension of phenomenal consciousness, and, therefore, opens the door at least to the consideration of whether cognitive mental episodes should also be taken into account when addressing the problems of phenomenal consciousness. ${ }^{3}$

In this paper I address the cognitive phenomenology debate, first, by presenting the motivation for cognitive phenomenology views and the main cases in favour of such views, taken as a challenge for restrictivism. Second, I critically examine two restrictivist positions: sensory restrictivism and accompanying states. I will then argue that neither position is successful in meeting the presented challenge and therefore cognitive phenomenology views hold up well against them.

${ }^{2}$ Terminology varies a lot here: Bayne (2009) labels the positions adopted as those of "phenomenal conservatives" versus "phenomenal liberals", Kriegel (2015) prefers "phenomenological inflationists" versus "phenomenological deflationists", and Siewert (2011) talks about "inclusivism" versus "exclusivism".

${ }^{3}$ One could say that debates about the reach of phenomenal consciousness focus mainly on high-level perceptual phenomenology and thus that issues on high-level perceptual phenomenology and cognitive phenomenology are independent, so that one could consistently accept the existence of one kind of phenomenology and deny the other. This is certainly the case, but there are reasons for considering both highlevel perceptual and cognitive phenomenology as questions relevantly tied within the issue of the reach of phenomenal consciousness. First, it seems, as a matter of fact, that most of the authors who accept high-level perceptual phenomenology also accept cognitive phenomenology (Bayne 2009, p. 404). And second, one important issue is at stake in both debates, namely, the question of whether conceptual representation has phenomenology or not. However, the relation between cognitive phenomenology and high-level perceptual phenomenology in relation to the reach of phenomenal consciousness debates has been highlighted here just for clarificatory purposes, given that the paper will be exclusively focused on cognitive phenomenology. 


\section{Cognitive Experiences: Motivation}

Examples of cognitive mental episodes abound: we normally entertain certain thoughts, such as the thought that doing philosophy is fun or the thought that two plus two equals four. And we also understand many written and heard sentences, which enable us to communicate. The case of understanding has been extensively used to motivate the idea of cognitive phenomenology, through the argumentative strategy of the phenomenal contrast argument (Husserl 1900-1901/1970; Peacocke 1998; Siewert 1998; Strawson 1994/2010; Horgan and Tienson 2002; Kriegel 2015; Chudnoff 2014). Strawson (1994/2010) offers a version of this argument: imagine two people listening to the news on a French radio program. One of them, Jacques, speaks French, while the other, Jack, only speaks English. We can ask whether Jacques, who understands what the news speaker is saying, has an experience of a different sort from Jack, who merely hears the French- sounding words without grasping their meaning. The issue is that their cognitive experiences are different although they have the same sensory experience (they hear the same chain of sounds). Jacques has an experience of understanding while Jack doesn't. As it can be seen from this example, phenomenal contrast arguments for cognitive phenomenology normally present two scenarios where there is a phenomenal difference from one to another and nevertheless the non-cognitive components (mainly sensory and perceptual aspects) remain the same. Since, it is argued, the only difference between the two scenarios is cognitive, the phenomenal contrast should be accounted for by appealing to cognitive phenomenology. At this stage it becomes clear that the kind of thought I am talking about and focusing on is occurrent conscious thought, thereby excluding from the focus dispositional cognitive mental episodes such as certain states of belief, for instance.

The crucial point in this argument is to know what accounts for the phenomenal change between understanding what someone tells you and not understanding it. ${ }^{4}$ Strawson argues for this understandingexperience over and above visual and auditory experience. The un-

${ }^{4}$ In Strawson's words: "consider what it is like, experientially, to hear someone speaking non-technically in a language that one understands. One understands what is said, and one undoubtedly has an experience. How do the understanding and the experience relate? Most will agree that the experience is complex, and that it is not merely sensory, not just a matter of the sounds. But they will hesitate if it is suggested that there is experience (as) of understanding" (Strawson 1994/2010, p. 5). The experience is "as" of understanding because it need not be veridical. "Misunderstanding involves understanding-experience as much as genuine understanding 
derstanding case can be construed with many different contents, but an appealing one is the understanding or grasping of a mathematical proof, for which it seems clear that when there is a phenomenal contrast between "getting" the proof and not getting it, the contrast is not due to any changes in the sensory inputs, precisely because no change occurs in the sensory material (see Chudnoff 2015b for the case of intuiting a mathematical proof).

Besides the experience of understanding, there are other interesting cases to motivate the view of cognitive phenomenology and that pose a challenge for restrictivism. One such case is the phenomenal contrast of the experience of counting in a certain familiar currency and counting in a foreign currency: the experience of getting the cost of familiar items, such as a lunch menu or a cup of tea, in our own currency, say Euros, compared to the experience of getting the cost of these same items in dollars, for instance. Another example may be a variation of the case applied to the counting experience in some countries before the creation of the Euro. Before 2000, in some European countries like Germany, France, Italy, Spain, etc., people were used to counting in the currencies of their own countries and so it was very common for people to find themselves in front of a shelf in a supermarket, seeing the prices of goods in Euros and then comparing them to those in their former currencies in order to have a sense of their value. This moment of comparison resembles the moment of understanding in that it is only through the comparison that the phenomenal difference between the two experiences (counting in your own currency versus counting in a foreign one) becomes evident. Before that, when seeing a bottle of wine with a price in a new currency, one does not have the experience of grasping its value at all.

The cognitive phenomenology view contends that cognitive experiences are given in a different way from sensory experiences. In terms familiar to the phenomenological tradition (and the works of Husserl, Sartre or Merleau-Ponty), we might say that we cannot equate the way certain intentional contents or objects appear in the thought mode of consciousness with the perceptual mode of consciousness. The idea is that the experience of thinking can - and maybe shouldbe given through images or other accompanying elements, but we undergo it and properly refer to it as such without taking these elements into account. Defenders of cognitive phenomenology put forward a view on the nature of the conscious character of thought does, for understanding-experience is experience as of understanding and need not be veridical. (It could be called "meaning-experience')" (Strawson 1994/2010, p. 7). 
in which cognitive phenomenology is one feature that must appear in the story as it serves to explain one element of conscious thought, that is, its specific phenomenal character. The claim that experiences of thinking possess a specific phenomenal character not reducible to sensory and emotional elements or states will be the main focus of this article along with the view of cognitive phenomenology that the restrictivist approaches considered here discuss. ${ }^{5}$

The phenomenal contrast arguments will be taken here just as motivation for cognitive phenomenology views, without discussing the virtues or problems of these kinds of arguments in more detail (for such a purpose see Chudnoff 2015a, 2015b, Koksvik forthcoming). The cognitive phenomenology view has been defended with different positive arguments of various sorts (Pitt 2004, 2009; Siewert 2011; Shields 2011; Nes 2012; Kriegel 2015; Jorba forthcoming, Jorba and Vicente 2014; Chudnoff 2015b, among others), but it is not my purpose here to explicitly argue for such a view. The aim is rather to explore the two main alternative views that form the restrictivist stance as I have presented it above. In order to do this, I will take the phenomenal contrast argument for cognitive cases as a challenge for those views to explain the very phenomenon that is presented. For simplicity, we can keep in mind the case of understanding a linguistic sentence and the experiential or phenomenal contrast that exists between the situation in which you do not grasp its meaning and the situation in which you do, all other elements remaining the same in both. After examining the two main restrictivist views, we shall see that this stance is not tenable as a view on the nature of the consciousness involved in thought. Given the strong dichotomy between restrictivists and expansionists upon which the debate on cognitive phenomenology has been construed, it should be relevant to undermine one such position and consider this strategy as philosophically interesting and as a step further in the discussion. Restrictivist positions have been assumed for decades in philosophy of mind and other fields of philosophy, and therefore shaking the grounds for

\footnotetext{
${ }^{5}$ Phenomenal contrast arguments are silent with respect to more specific claims, as for example, whether there is some specific phenomenology associated either with each content, or with each tokening of a particular content, or to different cognitive attitudes. It may be that all contents feel the same, as contentful utterances, or that there are distinctive cognitive phenomenal characters associated with different contents (Pitt 2004) or attitudes (Jorba forthcoming). Stronger modal claims have been made regarding cognitive phenomenology, like cognitive phenomenal character being necessary or essential for thinking (Pitt 2004), or cognitive phenomenal character partially grounding intentional content (Strawson 2008), but these are not the focus of discussion here.
} 
accepting these views and showing their instability will reveal new paths on the matter and enlarge the existing discussion.

\section{Restrictivism}

Restrictivism can be seen as the main stance against cognitive phenomenology views and one that deserves careful attention in order to evaluate the virtues and problems such positions may have. In this section I will provide a classificatory schema of restrictivist positions, also mentioning some possibilities in its logical space. This will be useful for rightly addressing our critique to particular positions within the general label of restrictivism, something that has not been done in the way proposed here in the literature.

The main claim of restrictivism is that there is no cognitive phenomenology, and so what we are looking at is a form of cognitive phenomenology eliminativism. This is to be distinguished from phenomenal eliminativist views simpliciter on the grounds that the latter deny any presence of phenomenology when consciously thinking, while the former just denies the presence of cognitive phenomenology when consciously thinking, something that will be relevant for our discussion in section 3.2.

The ways in which deniers of cognitive phenomenology present their positions can be classified according to two main parameters, which are often overlooked in the literature. One first parameter to consider is whether such non-cognitive phenomenology (i) is in fact one kind of more familiar phenomenology or it is rather (ii) a disjunction of different kinds of non-cognitive phenomenology (sensory, perceptual, emotional, etc.). A second parameter along which different views can be classified is whether the non-cognitive phenomenal character belongs to (a) the mental episode of thought by being a certain element or aspect of it, or rather to (b) another accompanying state or states that are related to or associated with thought. We thus have a second source of classification regarding the element/state distinction.

In this paper I will examine two main restrictivist positions. The first one, endorsed by Jesse Prinz, is an instance of the option (i)-(a), and I will call it "sensory restrictivism", and the second one, endorsed by Lormand (1996) and Tye and Wright (2011) is an example of (ii)-(b), and I will call it "accompanying states". 6 The remaining

${ }^{6}$ It should be noted that among restrictivist positions we can find another view that can be endorsed together with the ones examined in this paper, which claims that the conscious character of thought can be explained by appealing to access consciousness, without this implying the presence of phenomenal consciousness in 
options of combinations regarding the two criteria for classification, options (i)-(b) and (ii)-(a), are also conceptual possibilities, but we do not seem to find representatives of them in the literature. This may be for the following reasons. Certainly, endorsing (i)-(b) might not be a desirable position, as it amounts to saying that episodes of conscious thought are always accompanied by just one non-cognitive kind of mental episode, ${ }^{7}$ like perceptual states, which seems a strong claim for which we would need a principled reason. Is this unique non-cognitive episode perceptual, emotional? Or to which other category does it belong? And what reason do we have for considering this kind of accompanying episode the only kind that can be present? These sorts of questions seem to undermine the attractiveness of the position (i)-(b). As for possibility (ii)-(a), a disjunction of different non-cognitive elements, I think it remains an open possibility to be defended, although we do not seem to find clear examples in the literature. The reason for the difficulty of such a position may lie in the fact that it will be necessary to define what an "element" or an "aspect" of the mind is that has a perceptual or an emotional character, for example, without being part of a perceptual or emotional episode, respectively. If such an account is available, there does not seem to be any principled reason to deny venue (ii)-(a).

This double distinction is useful for classifying restrictivist positions because it disambiguates the existing views and sheds some light on them. It is worth noticing that the two options explored are not mutually exclusive, so one can plausibly maintain a restrictivist position that defends the existence of sensory elements in episodes of conscious thought and the existence of other associated states of a non-cognitive kind too. This seems to be the case of Peter Carruthers when he says: "thoughts aren't phenomenally conscious per se. Our thoughts aren't like anything, in the relevant sense, except to the extent that they might be associated with visual or other images or emotions, which will be phenomenally conscious by virtue of their quasi-sensory status" (2006, p. 6). Even if mixed positions like this one are also possible, it will become clear that they suffer from the

thought. For a criticism of this view, see Jorba and Vicente 2014. Another important argument in favour of restrictivist positions is the ontological argument raised by Tye and Wright (2011) following Geach $(1957 ; 1969)$ and Soteriou (2007). I problematize this view in Jorba 2015.

${ }^{7}$ By "non-cognitive kind of mental episodes" I mean mental episodes that are not cognitions (like perceptions, emotions, etc.) but I am not assuming that these other episodes do not or cannot have any cognitive element in them (such as conceptual content, for example). 
problems we encounter in sensory restrictivism and the accompanying states strategies. In addition, I consider the sensory restrictivism and accompanying-states views as the two strongest argumentative strategies against cognitive phenomenology views, and so ones that require detailed attention in order to correctly assess this side of the debate on cognitive phenomenology.

\subsection{Sensory Restrictivism}

The standard restrictivist response to phenomenal contrast arguments is to argue that non-cognitive elements do suffice to explain the phenomenal difference. This line of argumentation does not deny that there is a phenomenal contrast; rather, it denies that this contrast requires us to posit a distinctive cognitive phenomenology. As presented above, one prominent position within restrictivism claims that the phenomenology of conscious thought is to be accounted for with only one type of non-cognitive phenomenology, namely, sensory phenomenology. This strategy claims that in the phenomenal contrast in cognitive experiences like understanding, for example, some variation and difference among sensory elements suffices to explain the contrast. A proponent of this kind of reductionism is Jesse Prinz, whose general theory of phenomenal consciousness implies a restrictivist view on cognitive phenomenology.

Following Jackendoff (2007, 2012), Prinz (2002, 2005, 2012) has extensively argued for a general theory of consciousness according to which consciousness arises at the intermediate level of perceptual systems, where feature integration takes place and attention mechanisms are involved, ${ }^{8}$ that is, with attended intermediate-level representations, or AIRs. It is an intermediate level between the low-level stage that responds to local stimulus features without integration and the high-level perceptual stage that abstracts away details from the previous one. According to this theory, the neural correlates of perceptual consciousness are thus restricted to brain areas that implement this perceptual processing. The strategy here is to think that an account of perceptual experiences will give a general account of consciousness, so that the following conclusion serves as a slogan for the view: all consciousness is perceptual consciousness. ${ }^{9}$

\footnotetext{
${ }^{8}$ For Prinz, an intermediate-level mechanism is necessary but not sufficient for consciousness: attention is needed for consciousness to arise.

${ }^{9}$ Prinz argues for the particular claim that all phenomenal consciousness is perceptual phenomenal consciousness, although he believes other uses and forms of consciousness are parasitic on phenomenal consciousness, and thus this more general
} 
Prinz's argumentative strategy regarding specific cognitive phenomenology is mainly negative, as he tries to account for the cases in favour of cognitive phenomenology with the resources of his perceptual view of consciousness. ${ }^{10}$ He argues that conscious thought "feels like" something (there is a phenomenology), but not that it feels differently than sensory activity (all phenomenology is in fact sensory experience). He then tries to accommodate the phenomenal contrast between cases of understanding and not understanding something, and similar ones, to differences in sensory elements, such as different associated mental images or inner speech or differences in the focus of attention.

If we focus on Prinz's theory of AIRs, we can see that the problems for his sensory view can arise in all those domains that outstrip the intermediate level. This is the case with high-level perceptual representations, perceptual constancies, the experience of presence in absence, motor actions, and emotions. If some of these domains exhibit a distinctive phenomenology, then Prinz's theory is undermined. ${ }^{11}$ Regardless of whether these cases succeed, I will focus on two main problems: the role of attention and the role of phenomenal character. $^{12}$

Firstly, one available strategy for Prinz is to claim that what account for the phenomenal contrast are changes and shifts in attention. When we use concepts to categorize certain things, or when we see, for example, the ambiguous image of the duck/rabbit (see Wittgenstein 1953) as a duck or as a rabbit, the phenomenal difference may be explained by appealing to shifts in our attention to certain features of the figure in question (Prinz 2011, p. 183). The question is thus: can these shifts in attention explain the phenomenal difference in the understanding case? It is difficult to see how in this

claim can be defended (see Prinz 2007, p. 336). This view contrasts, for example, with Peacocke's 1983, according to which conscious thought is a special case of another kind of consciousness, namely, action consciousness. Action awareness is the other case, apart from thought awareness, that can provide objections to Prinz's view (Prinz 2007, p. 341).

${ }^{10}$ His positive stance consists in giving a diagnosis of the intuitions that guide expansionists in terms of introspective illusions. This move is not very successful in principle, given that expansionists could appeal to a similar kind of reasoning for the diagnosis of the intuitions that guide restrictivists: when they posit just sensory phenomenology, they are in fact being blind to other kinds of phenomenology.

${ }^{11}$ For a discussion of each of these domains, see Prinz 2011, pp. 178-181.

${ }^{12}$ I take Prinz as one of the main representatives of sensory restrictivism, although similar arguments like the ones presented here can be applied to other authors endorsing this view. 
case attention can be distributed differently in each instance so as to account for the phenomenal contrast. When we don't understand a sentence we are reading, do we focus more on the individual words, as opposed to focusing more on the whole sentence when we understand what we are reading? Certainly this can happen and attention surely affects phenomenology, but the point is that it is doubtful that this difference in attention distribution over the written words is what accounts for the phenomenal difference between understanding something you read and not understanding it —or at least it seems difficult to match this difference with the phenomenal difference we experience between understanding and not understanding, something the sensory restrictivist does not deny-. We have to be aware of the fact that this first objection is not committed to the idea that attention and understanding or reading comprehension are not relevantly related (which they are: Stern and Shalev 2013); it only discusses the claim that attention distribution over the written words, in this case, is what accounts for the phenomenal difference when understanding something. If we also take the case of counting in an old versus a new currency in the period after 2000 in the countries of the Eurozone, we face the same kind of difficulties. How are attention mechanisms to account for the phenomenal difference? It seems that no matter how hard you try to focus attentively on a price in one currency or in the other, or even in the calculation of the equivalence, attention cannot explain the phenomenal contrast.

Secondly, I will present a problem that needs some more discussion. It seems reasonable to say that our experience of thinking can be partly distinguished from other kinds of experiences (perceptual, emotional, etc.) on the basis of the experience itself. This means that just by way of undergoing a certain mental episode, by experiencing it, we are in a position to at least distinguish it from another kind of mental episode. Thus, if asked whether you are seeing an ice cream or whether you are thinking about it, your response seems to be immediately available to you on the basis of your current experience and its phenomenal character. The proposal of sensory phenomenal aspects does not seem to serve for distinguishing experiences of thinking from sensory or emotional ones on the basis of immediate experience. The point is that if the phenomenal character of perception and thought is of the same kind, namely, sensory, then there is no way, on the basis of experience, to distinguish between a perceptual experience and a conscious thought. ${ }^{13}$ For example, if

${ }^{13}$ Another criticism of sensory restrictivism can be found in Siewert's 2011, where 
we see an ice cream and if we consider whether this ice cream is too expensive (in the absence of the visual perception of the ice cream), and in both cases we have the same kind of phenomenal elements (a certain image, for example), then the mere experiential character cannot differentiate between the two mental episodes. ${ }^{14}$

A question that needs to be defended in this objection is the following: why am I claiming that it is on the basis of the phenomenal character of the experiences that we may tell them apart? I am supposing that the distinction between both kinds of mental episodes is immediately given in experience, and phenomenal character seems to be a good candidate for such a position. By "immediacy" I understand that such an operation of distinguishing is produced without need for conscious reasoning and is not based on behavioural evidence (more on this in the discussion below).

The proponent of sensory restrictivism has six possible replies to this objection, as far as I can see. I will examine them in detail in

he argues against restrictivist positions by appealing to a pair of situations, namely, reading with comprehension and without it and trying to explain the phenomenal difference between both by appealing merely to sensory elements. For that, he argues, the identification of some separable sensory features is required, which he concludes is not possible, thus rejecting what I call "sensory restrictivism". Although with many relevant differences, Siewert's argument is similar to mine in that it questions the role that sensory elements would have to have according to restrictivism.

${ }^{14}$ The distinguishability claim is also part of Pitt's (2004) epistemic argument in favour of cognitive phenomenology, to the conclusion that each type of conscious thought - each state of consciously thinking that $p$, for all thinkable contents $p$ has a proprietary, distinctive and individuative phenomenology. Pitt uses the fact that we can distinguish between thoughts and perceptions, that we can distinguish between different thought contents and that we can individuate thoughts to construe a transcendental argument to the effect that this fact would not be possible unless there is a proprietary, distinctive and individuative phenomenal character for thought. In this paper I am only discussing the proprietary claim: a proprietary (or specific) phenomenal character would allow us to distinguish a type phenomenology for thought among other kinds of states such as perceptions, imaginations or emotions. If we just take this claim from Pitt's argument, leaving aside the distinctiveness and individuative claims, we can see that there is an important difference in the use of the claim I am making here. The problem that I am raising for sensory restrictivism is stressing the fact that sensory restrictivism in particular cannot account for the experienced distinction between thinking and perceiving because the sensory accompaniments they propose would not suffice for that, given that they are elements of the same kind. This particular claim is not something Pitt directly discusses in the argument. For extended discussions of Pitt's whole argument and alternative models of self-knowledge, see Tye and Wright 2011, Levine 2011, and Chudnoff 2015b, and for an extension of Pitt's argument to cognitive attitudes, see Jorba forthcoming. 
what follows. The first possible reply is to argue that there might still be differences in the images and verbal speech of both episodes that can account for the phenomenal difference between the two. In response, we can say that the most we have are some sensory differences between a visual perception and the mere entertainment of a proposition, so we are left with nothing else that makes us aware that we are undergoing a visual experience (and not thinking about it), or considering whether the ice cream is expensive. The point here is that the only kind of phenomenal character involved in both episodes is the sensory kind, and this leaves unanswered the question of how the sensory kind is able to distinguish between these two experiences.

A second possible reply claims that sensory phenomenology is typified in a way that can do the job, so that the sensory elements of cognitive episodes are different from those involved in visual perception. If this were so, this restrictivist view has a way to account for the phenomenal contrast without supposing the existence of cognitive phenomenology. We might envisage several ways of cashing out this strategy. One way is to show that there is a complex combination of sensory elements in the case of thought that helps us to distinguish it from the seeing experience. But why should we suppose that this complex combination of sensory elements is present when we think and not when we see? In fact, things seem to be the other way around: visual experiences are richer in sensory elements than our experiences of thinking, where the sensory elements can be accompaniments but do not have the pervasive presence they have in visual experiences. Perhaps then, it is precisely this richness of the sensory elements in perception that gives the sensory reductionist a way out: sensory perceptual aspects are richer than sensory cognitive aspects and the subject is able to introspectively distinguish between both kinds of experiences on this basis. We do not find an explicit endorsement of such a claim in Prinz, but this certainly would help a restrictivist like him and seems a promising view to endorse. I think, however, that this response is also problematic, as it implies that ineffable aspects such as vividness or richness are able by themselves to "tell us" whether a given experience is perceptual or cognitive in kind. Indeed, this reply is in tension with the empiricist view of concepts that Prinz endorses (2002), according to which concepts are copies of perceptual representations and, arguably, the difference between the richness of the sensory phenomenology in perception and in cognition should be a matter of degree rather than a clearcut distinction between perception and thought. If it is a matter of 
degree, however, then it is not clear that the richness and vividness of either phenomenology can serve as criteria for identifying one kind of experience and excluding another, since the movement from perception to cognition (regarding phenomenology) will be a matter of degree. Focusing on sensory phenomenology, at which point does perception end and cognition begin? There does not seem to be a straightforwardly satisfying answer to this question available to sensory restrictivists.

A third possible reply, related to the previous point, can claim that other elements different from phenomenal character are responsible for our being able to distinguish both kinds of experiences. One version claims that it is by virtue of some inferential subpersonal mechanism that we can immediately distinguish between our occurrent perceptual experience and a cognitive one (in the way that Nichols and Stich 2003, or Cassam 2011 propose), and so we do not need to think that it is the phenomenal character that does the work. With respect to this, one might think that even if there is such a sub-personal mechanism, it has to have some effect or "show up" somehow at the level of experience. And if the difference shows up in the experience then it will make a phenomenal difference. Thus, regardless of the cause (the sub-personal mechanism) of our capacity to distinguish both kinds of mental states, if this distinction shows up in experience, then there is a phenomenal difference, and we can say it is through this that we come to know that we are having a thought and not a visual experience. However, whether the subpersonal mechanism account provides a satisfactory view of our capacity to discern between cognitive and perceptual episodes on the basis of immediate experience remains an empirical question insofar as the functioning and existence of such mechanism would have to be empirically proved for this case.

Another version of this reply might adduce that perhaps we can distinguish between both kinds of experiences by virtue of being aware of their distinct kinds of contents: perception represents more fine-grained contents and thought more course-grained and abstract contents, for instance. If so, there is no need to appeal to different kinds of sensory phenomenology, but rather the content itself of such experiences does the job. In response, notice that if sensory restrictivism follows that path, then it seems that it will be accepting an element in experience that outstrips sensory aspects, which would undermine the view itself. For Prinz (2011, p. 176), any content that goes beyond sensory appearance has no direct impact on experience and, thus, on phenomenology. The difference between fine-grained 
and course-grained contents, in this case, would be something that is not experienced, and so the appeal to such kinds of contents is not available to a sensory restrictivist like Prinz.

A fourth possible reply to the objection of the limitations of sensory phenomenology as regards explaining the distinction between visual and cognitive episodes on the basis of immediate experience is to deny the assumption of my objection and so to claim that there is no way to experientially and immediately distinguish between visual and cognitive experiences. But consider the consequences that this denial would have: merely thinking of an approaching tiger may not produce any bodily movement to escape, whereas visually perceiving that a tiger is approaching you would cause you to run in the opposite direction, at least in normal circumstances. If you were not able to immediately distinguish between undergoing an experience of thinking about a tiger or seeing one on the basis of your experience, this would surely be a major handicap for your life. And it seems implausible to claim that the phenomenal character of experience is so "incapable" as to be unable to provide this minimal information about the kind of mental state we are in, even if it is untrustworthy and subject to error.

A fifth reply available to sensory restrictivism is to say that the view is committed to being unable to differentiate between the perceptual and the cognitive episode, but that this would be the case only at the very moment of the experience. However, if we take a longer period of time then we obtain different inferential roles for distinguishing both episodes. This seems like an ad hoc solution to the problem presented, for how do we know what period of time has to elapse? How is the period of time to be established? Phenomenologically, it seems that we are able to differentiate between an experience of thinking and a perceptual experience without waiting a certain period of time, and we can do this on the simple basis of experience.

A sixth possible rejoinder to my objection is that I am not carefully distinguishing perception from imaging, and that once we recognize that perception does not reduce to imaging, i.e., to having certain images, then the sensory reductionist can account for the difference between the experiences of visual perception and thought by claiming that in thought, the sensory elements we have are mental images, while in visual perception, the sensory elements involved are not mental images, but colours, shapes, etc., as belonging to certain external objects. Both sensory components are different enough so 
as to provide the subject with a basis for telling apart thoughts from visual perceptions. This rejoinder could have some success were it not the case that endorsing it would give rise to another problem, namely, that thought (with sensory imagistic accompaniments) would not be distinguishable from other kinds of mental episodes different from perception that also involve images, like certain emotions or feelings. If someone is afraid of walking in the dark, for example, this person might have mental images accompanying (or perhaps partly constitutive of) the feeling of fear. If we take such an example, then the proponent of sensory reductionism would be committed to saying that we cannot distinguish this feeling of fear from, for instance, a thought about how fearful dark nights are, also involving such mental images. Therefore, even if this sixth rejoinder to my objection seems more plausible, I have pointed out that it entails further consequences regarding the ability to distinguish a feeling from a thought, for example, on the basis of experience, and this does not appear to be a desirable result for any account.

Now, to sum up: in this section I have highlighted two problems that the proponent of sensory restrictivism encounters. On the one hand, there is the implausibility of appealing to changes in attention in order to explain the phenomenal contrast in understanding and, on the other hand, there is the inability of this view to account for the fact that we can distinguish between different kinds of mental states (visual perceptual experiences from thought experiences, for example) on the basis of immediate experience. Regarding this second problem, I have considered six possible replies and have provided answers to them.

Before turning to the second kind of restrictivism, let me dispel a methodological worry that might have arisen so far. It has not been my intention to show that the discussion presented exhausts the resources available for the sensory restrictivist or that the view has to be ruled out by the existence of such problems. Perhaps a battery of counterexamples would never completely refute a position; nevertheless they would contribute to presenting sensory restrictivism as a view that many authors would be embarrassed to defend further.

\subsection{Accompanying States}

The second restrictivist strategy is accompanying states: the phenomenology of conscious thought is to be accounted for by a disjunction of different non-cognitive types of phenomenal states. In comparison with sensory restrictivism, this strategy might seem more 
compelling, as it allows for more options, and thus has more chances to succeed.

Lormand (1996) was the first to dispute Goldman's (1993) revival of the cognitive phenomenology debate in a reductionist way. $\mathrm{He}$ contends that propositional attitudes are only accompanied by associated states, and it is these states and not the propositional attitude itself that have the qualitative character (Lormand 1996, pp. 246247). He proposes the qualitative quartet as the legitimate bearers of phenomenal character. The quartet is composed of the following kinds of mental states: (i) conscious perceptual representations, such as tastings and visual experiences, (ii) conscious bodily sensations, such as pains, tickles and itches, (iii) conscious imaginings, such as those of one's own actions or perceptions, (iv) conscious streams (or trains) of thought, as in thinking "in words" or "in images".

This strategy is exhausted by these four kinds of states. A proposal along these lines is presented by Tye and Wright (2011). It is similar to Lormand's in almost all respects, with the difference that they add (without any explicit reason) other kinds of states, that is, primary emotional experiences, such as feeling anger or fear, and the experience of effort:

from a phenomenological perspective, thinking a thought is much like running a sentence through one's head and/or (in some cases) having a mental image in mind together with (in some cases) an emotional/bodily response and a feeling of effort if the thought is complex or difficult to grasp. (2011, p. 329)

In what follows, I shall explore this kind of accompanying-states view.

If we come back to the cases that motivate cognitive phenomenology views and the phenomenal contrast, we can add the idea that the phenomenal contrast strategy can be complemented by the presentation of singular cases in which, if there is experience or phenomenal character, the sensory or non-cognitive elements do not seem to suffice to explain it. A particularly interesting case, due to its being at the limit, is the case of what can be called pure abstract thought. Is pure abstract thought possible? If it is possible to consciously entertain a pure abstract thought without any of the mentioned accompanying states being present, then this would be a counterexample for the accompanying-states view. What would its proponents say in those cases? They would probably deny that there is any phenomenology involved in such cases, were it possible. Some authors, 
like Robinson (2005), have taken cases in which there is no possible sensory-imagistic accompaniment as evidence for the claim that there is no cognitive phenomenology. This holds, however, only if one operates with a sense of phenomenal character restricted by definition to the sensory domain or to sensory-like elements. But if we recognize a certain experience and phenomenal consciousness when consciously thinking (as the accompanying-states view actually does), then what would it mean to consciously entertain a pure abstract thought without phenomenal character? ${ }^{15}$ It is worth noticing that the problem for accompanying states that I am trying to put forward does not presuppose the existence of pure abstract thought in isolation from all sensory experiences whatsoever, so the view may be compatible with the claim that pure abstract thought is founded or grounded, for example, in sensory and perceptual experiences, in the sense that some kind of sensory or perceptual experience has had to occur at some point for the pure abstract thought to be possible. ${ }^{16}$ But this does not imply that these sensory and perceptual experiences, or elements of them, are present when the pure abstract thought occurs or that they give the pure abstract thought its phenomenal character. This last issue is what is at stake. Let us now consider this: if there are pure abstract thoughts, then the following possibilities emerge (in relation to non-pure abstract thoughts):

1) There is no phenomenal character in pure abstract thought. With this possibility, two other options are available: (a) Nonpure abstract thoughts do not have cognitive phenomenology, only non-cognitive kinds of phenomenology ${ }^{17}$ or (b) Non-pure abstract thoughts do have cognitive phenomenology (maybe jointly with other non-cognitive phenomenology).

2) There is cognitive phenomenology in pure abstract thought. This would open two more possibilities: (a) There is also cognitive phenomenology in non-pure abstract thought or (b) There is no cognitive phenomenology in non-pure abstract thoughts.

${ }^{15}$ Prinz (2011) considers cases of imageless thought and languageless thought in turn and argues that they do not provide evidence for cognitive phenomenology, but he does not directly address the case of pure abstract thought.

${ }^{16}$ In this sense, my approach here is not undermined by Pautz's (2013) arguments to the conclusion that it is not true that cognitive phenomenal properties are completely modal-independent of sensory-functional conditions.

${ }^{17}$ Among non-pure abstract thoughts there is also the possibility of not having phenomenology at all, and this would amount to the phenomenal eliminativist approach considered above. 
All these possibilities are conceptual possibilities. Among the possibilities open in 1, (la) seems to be more reasonable: if there is no cognitive phenomenology in pure abstract thought, then I do not see why there should be this kind of phenomenal character in the non-pure abstract thoughts and other kind of thoughts. If this were so, the extreme case of pure abstract thought is not very helpful for our analysis. Among the possibilities open by 2, (2b) is quite difficult to defend, because it attributes cognitive phenomenology only to pure abstract thought and not to all the other cases, but then this alleged kind of cognitive phenomenology of pure abstract thought would just appear in this extreme case, which seems not very plausible. One reason why I think it is reasonable to discard (lb) and (2b) is the appeal to a certain phenomenal continuity in conscious thought, the idea that there is no radical change in cognitive phenomenology among different kinds of thought (pure and non-pure). The phenomenal continuity claim has been used as applied to our mental lives, from sensory perception to perceptual perception or thought (Klausen 2008). Whether or not this claim stands for the whole mental domain, here we just need phenomenal continuity to hold between the two cognitive cases of pure and non-pure abstract thought as a motivation to dispel (1b) and (2b). Both options would deny the phenomenal continuity claim, but in different ways. As for (lb), the difference between pure and non-pure abstract thought would amount to the subject ceasing to be phenomenally conscious in pure abstract thought, while she is phenomenally conscious in all other cognitive cases, which is a very strange result. And as for (2b), the way of defeating the phenomenal continuity claim is by saying that the subject begins to be cognitively phenomenally conscious just in pure-abstract thought, which also seems very ad hoc. It seems reasonable, therefore, to confine ourselves to the following two possibilities:

la) There is no cognitive phenomenology in pure abstract thought and the same applies to all other kinds of thought.

2a) There is cognitive phenomenology in pure abstract thought and this is evidence that it is also present in non-pure abstract thought.

Thus, it seems that if we can find evidence for the extreme case of pure abstract thought, we would have evidence for (2a) and, with this, we would have made a problematic case for the accompanying states 
view (and also for sensory restrictivism as far as it needs the presence of sensory elements of the cognitive state). Moreover, this would help us to avoid a certain skepticism on the dialectics between defenders of accompanying states and defenders of cognitive phenomenology, in which the appeal to concrete cases does not seem able to solve the question (Jorba 2011). The difficult task is precisely to find evidence for these extreme cases, given that in most of our conscious thinking, the presence of images, inner speech and other accompaniments is so pervasive (Klinger and Cox 1987-1988; Hurlburt and Heavy 2006). There have been arguments for the plausibility of what I have been calling "pure abstract thought" by appealing to thought-experiments (Kriegel 2015) and by considering a specific kind of phenomenal contrast argument (Chudnoff 2015a, Chudnoff 2015b). However, my aim here will be to point to and discuss some empirical evidence that can provide a case for pure abstract thought.

In the scarce empirical research directly investigating our topic, we find some experiments that aim to support the existence of unsymbolized thinking. ${ }^{18}$ With the Descriptive Experience Sampling (DES) method, Hurlburt and Akhter (2008) defend the thesis of the existence of an explicit, differentiated thought experience that does not include the experience of words, images or any other symbols. They argue that it is one of the five most common features of inner experience, together with inner speech, inner seeing, feelings, and sensory awareness. They do not seek to show that it is omnipresent, but that it exists as experience. In their work, they acknowledge that

despite its high frequency of occurrence across many individuals, and despite (or perhaps because of) its potentially substantial theoretical importance, many people, including many professional students of consciousness, believe that a thinking experience that does not involve symbols is impossible; in fact, such phenomena are rarely discussed. (2008, p. 1365)

They attribute this lack of attention to, among other things, the prejudice of scientists and philosophers that all thinking must be in

\footnotetext{
${ }^{18}$ Hurlburt and Akhter do not call it pure abstract thought because they think this commonly refers to a "state cultivated by serious practitioners of some contemplative traditions" (Hurlburt and Akhter 2008, p. 1368) and this allegedly implies some enlightenment of these subjects over the other ones. I do not find this a convincing reason for not using the label "pure abstract thought" and I do not think this implication is contained within this label or it is even implied contextually, more generally.
} 
words. Their aim is to contribute empirically to highlighting and describing different kinds of inner experiences. They show the presence of unsymbolized thinking mainly through an interview they perform with subjects after some days of sampling in which the latter annotate what was going on in their experiences when a random beep sounds in their daily environments. From the sampling experience they focus on some extracts from the reports of the subjects, like these: ${ }^{19}$

1. I wonder how much cheaper that is than Cox Cable?

2. I wonder if Cox ... how much cheaper this NetZero could be than Cox Cable.

3. I wonder, y'know, if this is actually cheaper.

4. I wonder if it's really that much cheaper?

5. Thinking of. .. Cox Cable versus NetZero.

They acknowledge the difference in expressions in all these statements, even though they preserve the same meaning. ${ }^{20}$ It seems to be a mark of unsymbolized thought that the reports vary so much and subjects are less confident about them than in cases where inner speech is involved, where subjects are more confident of the exact words used in their thinking. A second aspect that, according to these authors, points to this phenomenon is that the subject appears to be helpless, powerless in the face of her own observation of her experience, by conveying expressions like: "I know this sounds weird, and I don't think it's really possible, but you asked me to tell you exactly what is in my experience and this is it. Sorry if it didn't conform to your expectations, but this is what I was thinking" (Hurlburt and Akhter 2008, p. 1366). A third indicator is that although the interviewers give her the chance to provide less controversial descriptions of her experience by asking her whether it was in words or in pictures or images, etc., she sticks to her description. Fourth, the use of "I wonder" to introduce the description of their thoughts is a mark of unsymbolized thought, but the researchers recognize that this cannot

${ }^{19}$ See Hurlburt and Akhter (2008, pp. 1365-1366) for a detailed explanation.

${ }^{20}$ One could think that at most this statement shows the presence of an unconscious common thought, for which we have various conscious expressions. Even if this is a possible interpretation of the phenomenon, such an interpretation would be incompatible with the reports of the subjects that state that this phenomenon is experienced (see below), and so the main data of the experiment would have to be mistrusted. 
be a rule, given that many wonderings may in fact involve images and inner speech, and other cases of unsymbolized thought might not be introduced by "I wonder" in the reports (perhaps merely an "I am thinking"). So this is a clue rather than a rule for the presence of this phenomenon. ${ }^{21}$

Once these indicators have been clarified, Hurlburt and Akhter present in more detail what exactly unsymbolized thinking is. The first point they suggest is that it is a complete phenomenon on its own, so that it is not a part or something unfinished, vague, deficient, or implied by some other phenomenon. It stands at the same level as inner speech and other well-known phenomena. Second, it is a way of experiencing that is directly apprehensible without need for inferences. Third, it is experienced as thinking, and not as a feeling, not as an intention, nor as an intimation or a bodily event. Fourth, the content of the thinking is explicit: subjects easily report what they are thinking; and, fifth, this content is differentiated, that is, it is not vague or general. Sixth, and significantly, they claim that the content of the thought is directly in experience; it is not the case that the mere "title" of the thought is experienced and the rest is not conscious, or that the unsymbolized thought is a precursor of the symbolic one. Seventh, this phenomenon presents itself all at once as a unit (without rhythm or cadence, neither unfolding nor sequentially). Thus there is no separation between the subject and the predicate of the thought, even if it can be said that it has this structure (and this contrasts with thinking when there is inner speech). Eighth and finally, unsymbolized thought does not include the experience of words, images or any other symbols. Subjects that experience it as a main phenomenon do not "say to themselves" some words, nor hear any words, nor see any words, or experience words in some other modality.

${ }^{21}$ In addition to these marks, the researchers identified other cases in which unsymbolized thought is not the main or the only feature of experience (as in the case presented) but is rather part of a more complex inner experience that may include other instances of unsymbolized thinking, inner speech, inner seeing, and other kinds of experiences. Perhaps these simultaneous experiences would be discovered not to be simultaneous if we had access to the underlying processes of thinking, but the DES method does not answer this question and remains at the level of experience, in which the mentioned subject experiences them simultaneously. This feature of the method is an important one, as the results on unsymbolized thinking do not imply anything else at the neuronal level or between the relation of this experience to underlying phenomena and its integration into theories of thought or consciousness. 
It is notable that, unlike in other phenomenological empirical studies of experience, unsymbolized thinking is not something the researchers set out with the aim of eliciting from the subjects, but it is something that emerges when they start with no target concept and carefully ask subjects to describe randomly selected everyday experiences. Unsymbolized thinking appears then in the end of the research and not at the starting point. If the presence of such a phenomenon can be established empirically in this way, then it seems that we have evidence of an experience that the accompanying-states view has to accept as having cognitive phenomenology, precisely because they do not deny that there is an experience when consciously thinking; they just deny that this experience has cognitive phenomenal character. The case of unsymbolized thinking can thus be interpreted as that in which there is an experience in the absence of any sensory material. ${ }^{22}$

However, the DES method has not gone unquestioned. There is of course resistance to accepting these results, and Carruthers (1996) considers Hurlburt's reports of unsymbolized thinking and raises objections to them. He accepts that people sometimes do think without images or words, but denies that such thoughts are conscious. Relying on the reports of Nisbett and Wilson's 1977, the main point of his criticism is that subjects' reports are not in fact based on direct observation of the phenomena but they are rather a selfinterpretation of their thinking. Therefore they are confused about their reports. Tye and Wright (2011, p. 335) also note the difficulty in suggesting that the alleged unsymbolized thoughts are cases in which the subject may indeed not be thinking at all. Now it seems that the (old and) pervasive problems of the interpretation of introspective reports can have a substantial effect on the empirical results Hurlburt and colleagues put forward on unsymbolized thinking.

In fact, Hurlburt and Akhter acknowledge that this self-interpretation is possible and indeed has occurred when subjects gave reports about inner speech, which they confused with some other phenomena (unsymbolized thought, sensory awareness or some other complex experience), and is more frequent when subjects report inner speech and images than in unsymbolized thought cases. This is because of the distress some subjects initially experience when reporting unsymbolized thinking (Hurlburt and Akhter 2008, p. 1371). They further suggest that if the argument from Carruthers holds, and the state

${ }^{22}$ See Martínez-Manrique and Vicente 2015 (p. 11) for the hypothesis that unsymbolized thinking "is roughly the beginning of a speech act that never became verbally realized". 
is not conscious, it holds across the board and might be levelled against all introspective reports of inner speech, visual imagery, and so on. But this does not seem a very good result for all experiments involving reports of first-person experience, which nevertheless are common in scientific studies of consciousness. Indeed, they add that if Carruthers' claim were true, it remains unexplained why subjects would hit upon unsymbolized thinking when searching for a plausible self-interpretation and also believing (as a presupposition) that all thinking occurs in words. Thus, we are facing an asymmetry: "It is thus easy to imagine a person giving an inner-speech explanation for an unsymbolized experience, but it is not at all easy to imagine a person giving an unsymbolized thinking explanation for a verbal (or absent) experience" (Hurlburt and Akhter 2008, p. 1371).

With respect to this, one of the features of the method is that the researchers are aware of this danger and they carefully study the differences between the actual experience and what subjects think or say about it. The way to do this is by having different descriptions of sampled experiences and careful interviews in which the investigator and the subject go deeper into the description of the experience. Moreover, a feature of the method that they think can meet Carruthers' challenge is that subjects are asked to write down their experiences quickly after the sound of the beep; afterwards, in the interview, triggered-by-the-beep thoughts and the like are left out. Their method is therefore not a brute appeal to introspective reports or armchair introspection (which they certainly attribute to Carruthers' view), ${ }^{23}$ but rather requires subsequent work on these reports and on various sampled experiences.

A further objection Tye and Wright (2011, p. 335) offer and which, to my knowledge, remains unanswered, is that the subjects' inability to provide any consistent description of the content of such thoughts does not entail that they had no associated imagery. The first reason for this is that having one's attention drawn to the noise of the beeper and to the task of recording one's experiences may

${ }^{23}$ An example of armchair introspection would be this: "So what one needs to do, firstly, is to introspect while (or shortly after) using some sentence of the natural language in the course of one's daily life; and secondly, while (or shortly after) one has been entertaining privately some complete thought, or sequence of such thoughts. In the first sort of case, what one discovers [...] is that there is often no separable mental process accompanying the utterance of the sentence itself; or, at least, not one that is available to consciousness. In the second sort of case what one discovers, I believe, is that our private thoughts consist chiefly of deployments of natural language sentences in imagination -inner thinking is mostly done in inner speech" (Carruthers 1996, p. 50). 
have a masking effect, thus undermining the ability of the subject to access imagistic vehicles for their previous thought's contents. And the second reason is that it should not be surprising that this inability is present, given that it could stem from the non-linguistic nature of imagery. However, notice the two following things. With respect to the second reason, it is true that the non-linguistic nature of the imagery can explain why subjects do not provide consistent descriptions of the contents of their thoughts, but Hurlburt and Akhter's point is rather that the subjects show this inability once it is clear that there are neither images nor inner speech present in their cognitive experience. Indeed, and with respect to the first reason, if there is a masking effect that prevents the subject from having access to the images, then we need a reason to think that this effect is in place in these cases and not in the cases where imagistic thoughts are reported, where the subjects clearly report the presence of images without problems. ${ }^{24}$ Besides, there is a second problem that Hurlburt himself mentioned in a conference as a response to this kind of objection. ${ }^{25}$ He argued that if the masking effect didn't allow subjects to access imagistic vehicles, then all subjects would report having unsymbolized thinking, given that the beeper would have masking effect in all subjects, at least sometimes. But there are people that do not report unsymbolized thinking at all. If this is so, then, how can the masking hypothesis explain the fact that some people do not experience unsymbolized thinking?

Actually, Hurlburt and Akhter do not claim that every occurrence of thinking occurs in the absence of imagery, and consistently admit that imagery is present in a lot of cases, but still they provide reasons to believe in the existence of this particular experience: the resistance

${ }^{24}$ A further pressing venue at this point would be to appeal to an error theory, stating that subjects may well believe that there is no associated imagery but this would in fact be false, given the unreliability of introspective reports. The unreliability of introspection (which the authors working with DES also accept) does not mean that introspection is always incorrect, so the error theory defender for unsymbolized thinking would need to provide a reason for distinguishing cases of error from cases of correct description, on pain of denying that introspection always leads to the wrong results. This last claim is something Hurlburt et al. would certainly not accept. Again then, the error theorist would have to say why a massive error occurs in the alleged cases of unsymbolized thinking and not when the subject clearly reports images in her experience.

${ }^{25}$ I am thankful to Agustín Vicente for mentioning this response that Russell Hurlburt presented in the Conference Inner Speech: Theories and Models, Granada, 1-3 July, 2015. See <http://granadainnerspeech.wix.com/workshop > [last retrieved: $11 / 11 / 2015]$. 
of the subject to describing her experience as containing images or the lack of confidence in the spelling out of the thought in words despite, in other cases, being able to say directly that there were images or simply report the words produced in inner speech.

The above arguments lead me to believe that the experience of unsymbolized thinking presents an important empirical counterexample to both kinds of restrictivism. I have reviewed some of the discussion regarding the DES method and the existence of unsymbolized thinking and I have also answered Tye and Wright's objection that subjects' inability to provide any consistent description of the content of such thoughts does not entail that they had no associated imagery. At this point, then, I think restrictivists would need something more than what they have adduced so far in order to dispense with such a challenge.

\section{Conclusions}

In this paper I have examined in detail one prominent position in the cognitive phenomenology debate, restrictivism. As presented above, the views that restrictivism includes accept the existence of phenomenology when consciously thinking (either in the form of non-cognitive elements belonging to that state or as necessary associated non-cognitive states) and account for it in terms of sensory or other non-cognitive phenomenology. As we have seen, both views can be adopted together and sometimes form a position that is taken for granted in philosophy of mind.

I presented examples of cognitive experiences as a challenge to restrictivist views and I then argued that restrictivism in its diverse forms cannot successfully respond to the challenge in either of its two forms: sensory restrictivism and accompanying states. On the one hand, sensory restrictivism faces the implausibility of appealing to changes in attention in order to explain the phenomenal contrast between understanding and not understanding; moreover, it has no resources to account for the fact that we can distinguish between different kinds of mental states on the basis of immediate experience. On the other hand, accompanying-states views seem a more powerful strategy, but they also fail to account for the case of pure abstract thought, which I tried to make plausible, both conceptually and empirically. Given that the DES method is not uncontroversial, I have suggested ways of dispelling the problems this method involves in relation to the presence of unsymbolized thinking. 
In this light I conclude that restrictivism in the forms examined here does not provide a valid characterization of the nature of occurrent conscious thought in relation to phenomenal consciousness. Sensory restrictivism and the accompanying-states views are thus not successful strategies in meeting the presented challenge from cognitive phenomenology positions. Therefore, defenders of cognitive phenomenology hold up well against detractors. ${ }^{26}$

\section{REFERENCES}

Bayne, T., 2009, "Perception and the Reach of Phenomenal Content", The Philosophical Quarterly, vol. 59, no. 236, pp. 385-404.

Bayne, T. and M. Montague (eds.), 201la, Cognitive Phenomenology, Oxford University Press, Oxford/New York.

- 2011b, “Cognitive Phenomenology: An Introduction", in Bayne and Montague 201la, pp. 2-34.

Carruthers, P., 2006, "Conscious Experience versus Conscious Thought", in U. Kriegel, and K. Williford (eds.), Self-Representational Approaches to Consciousness, The MIT Press, Cambridge, Mass., pp. 299-320.

—, 1996, Language, Thought and Consciousness. An Essay in Psychology, Cambridge University Press, Cambridge.

Carruthers, P. and B. Veillet, 2011, "The Case Against Cognitive Phenomenology", in Bayne and Montague 201la, pp. 35-56.

Cassam, Q., 2011, "Knowing What You Believe", Proceedings of the Aristotelian Society, vol. 111, no. 1 (pt1), pp. 1-23.

Chudnoff, E., 2015a, "Phenomenal Contrast Arguments for Cognitive Phenomenology", Philosophy and Phenomenological Research, vol. 90, no. 2, pp. 82-104.

, 2015b, Cognitive Phenomenology, Routledge, London /New York. , 2011, "The Nature of Intuitive Justification", Philosophical Studies, vol. 153, pp. 313-333.

Geach, P., 1969, God and the Soul, Routledge and Kegan Paul, London.

${ }^{26}$ I would like to thank Francesc Pereña and Manuel García-Carpintero for their helpful comments on various previous drafts of this paper. I am also grateful to the audience in the XXII SIUCC held in Donosti in September 2012, where previous versions of this work were presented, and specially to Jesse Prinz for helpful discussions on some parts of the paper. I am also indebted to two anonymous referees of Crítica for their comments and criticisms to a previous draft. Financial support for my work was provided by the DGI, Spanish Government, research projects FFI2010-16049 and FFI2013-47948-P, by the Perspectival Thoughts and Facts Project (PERSP) of the Spanish research and training network funded by the Consolider-Ingenio 2010 Scheme (CSD2009-00056), Spanish Ministry of Science and Innovation, and by the FPU Program of the Spanish Ministry of Education and Science (2008-2012). 
Geach, P., 1957, Mental Acts: Their Content and Their Objects, Routledge and Kegan Paul, London.

Goldman, A., 1993, "The Psychology of Folk Psychology", Behavioral and Brain Sciences, vol. 16, no. 1, pp. 15-28.

Horgan, T.E. and J.L. Tienson, 2002, "The Intentionality of Phenomenology and the Phenomenology of Intentionality", in D. Chalmers (ed.), Philosophy of Mind: Classical and Contemporary Readings, Oxford University Press, New York, pp. 520-533.

Hurlburt, R. and S.A. Akhter, 2008, "Unsymbolized Thinking", Consciousness and Cognition, vol. 17, no. 4, pp. 1364-1374.

Hurlburt, R.T. and C.L. Heavy, 2006, Exploring Inner Experience. The Descriptive Experience Sampling Method, John Benjamins, Amsterdam/Philadelphia.

Husserl, E., 1900-1901/1970, Logical Investigations, trans. J.N. Findlay, Routledge, London/New York.

Jackendoff, R., 2012, A User's Guide to Thought and Meaning, Oxford University Press, Oxford/New York.

- 2007, Language, Consciousness, Culture. Essays on Mental Structure, The MIT Press, Cambridge, Mass./London.

- 1987, Consciousness and the Computational Mind, MIT Press, Cambridge, Mass.

Jorba, M., forthcoming, "Attitudinal Cognitive Phenomenology and the Horizon of Possibilities", in T. Breyer and C. Gutland (eds.), Phenomenology of Thinking. Philosophical Investigations into the Character of Cognitive Experiences, Routledge, London, pp. 77-96.

Jorba, M., 2015, "Thoughts, Processive Character and the Stream of Consciousness", International Journal of Philosophical Studies, vol. 23, no. 5 , pp. 730-753.

Jorba, M. and A. Vicente, 2014, "Cognitive Phenomenology, Access to Contents and Inner Speech", Journal of Consciousness Studies, vol. 21, nos. 9-10, pp. 74-99.

Jorba Grau, M., 2011, “Thinking and Phenomenal Consciousness", Balkan Journal of Philosophy, vol. 3, no. 1, pp. 101-110.

Klausen, S., 2008, "The Phenomenology of Propositional Attitudes", Phenomenology and the Cognitive Sciences, vol. 7, no. 4, pp. 445-462.

Klinger, E. and W.M. Cox, 1987-1988, "Dimensions of Thought Flow in Everyday Life", Imagination, Cognition and Personality, vol. 7, pp. 105-128.

Koksvik, O., forthcoming, "Phenomenal Contrast: A Critique", American Philosophical Quarterly.

Kriegel, U., 2015, The Varieties of Consciousness, Oxford University Press, New York.

Kriegel, U. (ed.), 2013, Phenomenal Intentionality, Oxford University Press, New York. 
Levine, J., 2011, "On the Phenomenology of Thought", in Bayne and Montague 201la, pp. 103-120.

Lormand, E., 1996, “Nonphenomenal Consciousness", Noûs, vol. 30, no. 2, pp. 242-261.

Martinez-Manrique, F. and A. Vicente, 2015, "The Activity View of Inner Speech", Frontiers in Psychology, vol. 6, no. 232, doi: 10.3389/fpsyg.2015.00232.

Nagel, T., 1974, "What Is It Like to Be a Bat?", Philosophical Review, vol. 83 , pp. $435-450$.

Nelkin, N., 1989, "Propositional Attitudes and Consciousness", Philosophy and Phenomenological Research, vol. 49, pp. 413-430.

Nes, A., 2012, "Thematic Unity in the Phenomenology of Thinking", Philosophical Quarterly, vol. 62, no. 246, pp. 84-105.

Nichols, S. and S.P. Stich, 2003, Mindreading. An Integrated Account of Pretence, Self-Awareness, and Understanding Other Minds, Oxford University Press, Oxford.

Nisbett, R.E. and T.D. Wilson, 1977, "Telling More than We Can Know: Verbal Reports on Mental Processes", Psychological Review, vol. 84, no. 3, pp. 231-259.

Pautz, A., 2013, "Does Phenomenology Ground Mental Content?", in Kriegel 2013, pp. 194-234.

Peacocke, C., 1998, "Conscious Attitudes, Attention, and Self-Knowledge", in C. Wright, B. Smith, and C. Macdonald (eds.), Knowing Our Own Minds, Oxford University Press, Oxford.

- 1983, Sense and Content: Experience, Thought, and Their Relations, Oxford University Press, Oxford.

Pitt, D., 2009, “Intentional Psychologism”, Philosophical Studies, vol. 146, no. 1, pp. 117-138.

- 2004, "The Phenomenology of Cognition or What Is It Like to Think that P?", Philosophy and Phenomenological Research, vol. 69, no. 1, pp. 1-36.

Prinz, J.J., 2012, The Conscious Brain. How Attention Engenders Experience, Oxford University Press, Oxford.

- 2011, "The Sensory Basis of Cognitive Phenomenology", in Bayne and Montague 201la, pp. 175-196.

, 2007, "All Consciousness is Perceptual", in B.P. McLaughlin and J. Cohen (eds.), Contemporary Debates in Philosophy of Mind, Blackwell, Malden/Oxford, pp. 335-354.

- 2005, "A Neurofunctional Theory of Consciousness", Consciousness and Cognition, vol. 9, no. 2, pp. 243-259.

2002, Furnishing the Mind: Concepts and Their Perceptual Basis, The MIT Press, Cambridge, Mass./London.

Robinson, W., 2005, "Thoughts without Distinctive Non-Imagistic Phenomenology", Philosophy and Phenomenological Research, vol. 70, no. 3, pp. 534-561. 
Shields, Ch., 2011, "On Behalf of Cognitive Phenomenology", in Bayne and Montague 2011a, pp. 215-235.

Siewert, C., 2011, "Phenomenal Thought", in Bayne and Montague 201la, pp. 236-267.

, 1998, The Significance of Consciousness, Princeton University Press, Princeton.

Smith, D.W., 2011, "Phenomenology of Consciously Thinking", in Bayne and Montague 2011a, pp. 345-372.

Soteriou, M., 2007, "Content and the Stream of Consciousness", Philosophical Perspectives, vol. 21, no. 1, pp. 543-568.

Stern, P. and L. Shalev, 2013, "The Role of Sustained Attention and Display Medium in Reading Comprehension among Adolescents with ADHD and without It", Research in Developmental Disabilities, vol. 34, no. 1, pp. 431-439.

Strawson, G., 2008, Real Materialism and Other Essays, Oxford University Press, New York.

— 1994/2010, Mental Reality, 2nd ed., The MIT Press, Cambridge, Mass./London.

Tye, M. and B. Wright, 2011, "Is There a Phenomenology of Thought?", in Bayne and Montague 201la, pp. 326-344.

Wittgenstein, L., 1953, Philosophical Investigations, Blackwell, Oxford.

Received: March 12, 2015; revised: August 25, 2015; accepted: September 21, 2015. 